\title{
Interrupción Legal del Embarazo en México: Entre el control patriarcal y la libertad del cuerpo femenino ${ }^{1}$
}

Luis Alfonso Guadarrama Rico - Universidad Autónoma del Estado de México aguadarrama.famecom@gmail.com

Jannet Valero Vilchis - Universidad Autónoma del Estado de México javavi3@gmail.com

Abstract: En el año 2007, después de una larga batalla con grupos conservadores de óptica patriarcal, machista y religiosa, la Ciudad de México despenalizó una causa más para Interrumpir Legalmente el Embarazo (ILE) dentro de las primeras 12 semanas de gravidez, si la mujer así la decide y sin más causa o motivo que su propia decisión.

En septiembre de 2019, el Estado de Oaxaca fue noticia al aprobar la ILE, también hasta la doceava semana; dicha entidad se convirtió en la segunda en todo el país. Desde aquel año 2007 hasta la fecha, más de 200 mil mujeres, procedentes de todo el territorio nacional, han acudido a este servicio de salud pública con que cuenta el Gobierno de la Ciudad de México.

Con base en el procesamiento de once macrovariables nominales contenidas en la base de datos proporcionada por la Secretaría de Salud de la Ciudad de México, generamos el perfil sociodemográfico de las mujeres que en México

\footnotetext{
${ }^{1}$ Este trabajo ha sido financiado por la Universidad Autónoma del Estado de México y por Red Internacional FAMECOM, A.C. Fue posible gracias a la intensa colaboración de mis colegas Sandra Lorena Padilla y Antonio Quintero, quienes incansablemente realizaron el acopio, sistematización y búsqueda de información que nutrió el presente artículo. Estamos en deuda, con lliana Guadarrama Varón, quien hizo posible que contaramos con el tiempo, los recursos y el equipo necesario para desarrollar este documento. David Arriaga, siempre generoso y paciente con nuestras recurrentes enmiendas, estuvo a cargo del diseño de gráficos y mapas.
} 


\section{Las nuevas narrativas, en el entorno social}

Universidad de La Laguna, diciembre de 2019

DOI (individual): 10.4185/cil2019-número ponencia

han optado por la ILE, durante el periodo que transcurrió entre enero de 2018 a mayo de 2019, es decir, un lapso de 17 meses.

Durante el periodo analizado, 22,715 mujeres, procedentes de todas las entidades del país, optaron por la ILE en la Ciudad de México; por el número de casos atendidos, según la entidad de procedencia, el primer lugar lo ocupó la propia Ciudad de México, el segundo, el Estado de México y, el tercero, el estado de Puebla; la edad promedio de las mujeres fue de 25.7 años; $66 \%$ declararon ser de religión católica; la escolaridad alcanzada fue con estudios de secundaria en $27 \%$ y de nivel medio superior (bachillerato) $46 \%$. Este procedimiento fue aplicado entre la cuarta y la novena semana de gestación en el $88 \%$ de las intervenciones, utilizando solamente medicamentos.

La ILE, aunque está circunscrita geopolíticamente a la Ciudad de México y, de manera reciente en el estado de Oaxaca, está atendiendo y protegiendo la vida, así como la dignidad, de un sector femenil vulnerable, que si bien cuenta con empleo, en su mayoría carece de seguridad social y, prácticamente un tercio de ellas no tiene empleo. Es indispensable que el Estado Mexicano, haga uso de su postura laica para hacer posible que este derecho humano sea una realidad en todo el país, para beneficio y protección de la salud sexual y reproductiva de las mujeres que, por distintas condiciones y motivos la requieren.

Palabras clave: Aborto; embarazo juvenil; salud y medios de comunicación; interrupción legal del embarazo; patriarcado; derechos humanos.

\section{Introducción}

El aborto, como práctica sociocultural, tiene larga data; podríamos decir que se hunde en la noche de los tiempos. Sin embargo, el debate público, legislativo y mediático acerca de la interrupción legal de la gestación es más reciente a escala internacional. El primer país en el mundo que contó con una ley que permitía el aborto fue la entonces Unión de Repúblicas Socialistas Soviéticas (URSS) en el año 1920. Años más tarde lo prohibió, de 1936 a 1955. 
En América Latina, Cuba lo despenalizó a partir de 1965. En lo que va del presente siglo un total de 20 países han aprobado las ILE; los más recientes fueron Irlanda, Macedona del norte y Australia (Singh, 2018).

Actualmente son 67 las naciones que permiten cesar legalmente el embarazo a petición de la gestante; unas lo aprueban dentro de las primeras 12 semanas, pero otras estipulan que es lícito solamente dentro de las primeras ocho semanas, mientras que otras lo amplían hasta las 24 semanas. Los periodos más amplios los aceptan Canadá, Países Bajos, Reino Unido y Singapur (Center For Reproductive Rights, 2019).

Por lo que toca a México, el aborto legal existe en México desde 1871 por diversas causales. El Código penal aprobado en el año 1931 incluyó por vez primera la no penalización del mismo si el embarazo había sido producto de violación (Lamas, 2017). A lo largo de estos 76 años, algunas causales fueron consideradas paulatinamente en la legislación mexicana. Actualmente se ha logrado que en las 32 entidades del país, el embarazo pueda suspenderse si es producto del delito de violación, aunque no siempre se denuncia ni se aplica. En caso de que la mujer encinta presente un cuadro clínico que ponga en riesgo su salud si continúa con la gestación, en 30 estados de la República Mexicana, la ley la protege para que se le pueda aplicar un aborto, si ella lo autoriza; solamente en Guanajuato y en Querétaro no está esta despenalizada esta causal.

Solamente en 16 entidades se permite el aborto si el producto presenta malformaciones genéticas o congénitas graves; en las restantes 16 legislaciones locales no está incluida esta causal. Aunque se presentan casos aislados y poco frecuentes, en 13 códigos penales está permitida la interrupción si fue producto de inseminación artificial no consentida. En los estados de Michoacán y Yucatán, su legislación permite la ILE cuando la madre acredite que vive en condiciones socioeconómicas precarias y que tiene tres hijos o más. 


\section{Las nuevas narrativas, en el entorno social}

Universidad de La Laguna, diciembre de 2019

DOI (individual): 10.4185/cil2019-número ponencia

Excepto en Tabasco y Nuevo León, en las restantes 30 entidades del país no se penaliza el aborto si este debe aplicarse (en realidad concluirse mediante intervención gineco-obstétrica) como resultado de un accidente o por condiciones biológicas que sufre la madre y que generan una interrupción casi siempre parcial; los códigos penales lo tipifican como aborto imprudencial o culposo (IPAS México, 2019).

El Código Penal de la Ciudad de México (CDMX) reformado en 2007, despenalizó el aborto dentro de las primeras 12 semanas de gravidez. Desde entonces, las mujeres que requieran suspender su gestación tienen acceso a los servicios de salud requeridos para el efecto y no tiene costo para ellas. El código mantiene la visión punitiva pasadas esas doce semanas de preñez. También se permite la interrupción por causas de violación, inseminación artificial, malformación congénita que provoquen daños físicos o mentales en el feto o, si la vida de la madre corre peligro. Una vez más, la capital del país acredita la visión que ostenta el Estado laico mexicano.

Si bien constituye un destacado punto de inflexión aquel logro del 24 de abril de 2007, por la mayoría de la Asamblea Legislativa del Distrito Federal (ALDF) en la actual Ciudad de México, debemos tener en consideración que fue el resultado de una larga lucha que toca fondo hasta el año 1936, con los primeros esfuerzos en este tema y que, repuntó de manera sostenida a partir de la década de los 70, durante el pasado siglo XX (Lamas, 2017).

En México, con mayor claridad a partir de 1989, los debates legislativos, públicos y mediáticos (tanto en la prensa como en la televisión de aquellos años) se han mantenido efervescentes. Los distintos movimientos feministas, diversas organizaciones de la sociedad civil; el peso que han desempeñado los tratados internacionales sobre los derechos y la protección a las mujeres, así como las distintas cumbres y conferencias internacionales, han aportado una fuerza significativa para impulsar la ILE en México. 
En contraparte, grupos conservadores, básicamente alimentados por una visión que emana del Estado Vaticano y de una amplia red de catedrales, iglesias, parroquias, instituciones públicas y privadas, organizaciones civiles, medios de comunicación, partidos políticos de derecha, cámaras de diputados, gobernadores, alcaldes y mandatarios del Poder Ejecutivo, mantienen una fuerte oposición a la ILE. Desde esa trinchera han logrado contrarrestar el avance de la despenalización del aborto dentro de las primeras 12 semanas de gestación, a petición de la mujer gestante (Zimmermann, 1994).

El control sobre el cuerpo y de la capacidad reproductiva de las mujeres continúa con fuerza en la mayor parte de México. Lamentablemente no es exclusivo de países como el nuestro, sino resultado de los imperativos que ha impuesto milenariamente el sistema patriarcal que, como lo ha señalado la historiadora y activista Gerda Lerner, está cifrado en que los hombres se han apropiado de la capacidad sexual y reproductiva de las mujeres; que se ha subordinado esa sexualidad mediante las leyes y códigos; que el patriarcado ha impuesto a toda persona de sexo femenino que se convierta en madre, so pena de faltar tanto a un mandato divino, así como del riesgo a convertirse en seres incompletos, desdichados, estigmatizados y castigados por las leyes (Lerner, 1986).

\section{Objetivo de la investigación}

En medio de este debate, de una pugna que permanecerá todavía varios años, hemos querido contribuir al avance sobre la aprobación de la ILE en las restantes 30 entidades de México, aportando datos e indicadores de especial relevancia sobre este asunto tanto de salud pública como de los Derechos Humanos de las mujeres y niñas. Consideramos que prima en la mentalidad de diversas personas o grupos sociales una serie de prejuicios y de nociones que obscurecen la reflexión y que deforman o se alejan de la realidad. 


\section{Método}

Para llevar a cabo el estudio, decidimos realizar un trabajo de corte socioestadístico, basado en la matriz de información médico-clínica que nos proporcionó la Secretaría de Salud de la Ciudad de México, en tanto es la única fuente oficial que --mediante su red de clínicas para la ILE-- concentra mensualmente la información de cada uno de los casos que se atienden confidencialmente.

El contenido de la solicitud de información estuvo cifrado en incluir aquellas variables socioeconómicas, geográficas y educativas que nos permitieran trazar el perfil de las mujeres que por distintas circunstancias han tenido que recurrir a la ILE en la Ciudad de México, haciendo uso de su derecho a la salud sexual y reproductiva, independientemente de su lugar de residencia, en tanto la CDMX recibe a toda mujer que acuda a solicitar dicho servicio de salud, sin distinción de ninguna índole.

La información que recibimos vía correo electrónico, por parte de la dependencia oficial referida, incluyó el periodo que va de enero de 2018 a mayo de 2019, es decir, 17 meses en total. Una vez revisado el archivo recibido, se aplicaron los procesos recomendados por el campo de la informática, para revisar, limpiar y preparar los datos. Se procedió a revisar y mejorar la calidad de la matriz de información, a fin de homologar cada registro para fines de análisis posterior (Sucha, 2014). Ello permitió asegurar la calidad de la información recibida. ${ }^{2}$

Una vez concluida esta ardua y farragosa tarea, clasificamos, filtramos y procesamos estadísticamente la información aportada la Secretaría de Salud de la CDMX, pero aportada cotidianamente por personal que labora en las 13 clínicas de la misma dependencia gubernamental.

2 Sandra Lorena Padilla llevó a cabo esta gigantesca tarea. Nuestro reconocimiento a su talento, capacidad, extraordinaria paciencia, especialidad y profesionalismo como socióloga para hacernos ver aspectos finos de la información, así como del procesamiento que paulatinamente realizamos. 
Las 11 macrovariables que se procesaron fueron las siguientes: Edad, entidad de residencia, escolaridad de la mujer, estado de conyugalidad, ocupación, derechohabiencia, religión declarada, número de hijos, número de semanas de gestación al momento de acudir a este medida, método aplicado por el personal de salud para efectuar la ILE y, parentesco de la persona que le acompañó a la clínica de la ILE. A continuación presentamos los principales hallazgos obtenidos en la presente investigación.

\section{Resultados}

Durante los 17 meses observados, un total de 22,715 mujeres acudieron a la red de clínicas de la CDMX, a fin de recibir el servicio de la ILE. En promedio, cada mes se aplicaron 1336 interrupciones, es decir, 45 mujeres atendidas diariamente, ejerciendo su libertad sobre su cuerpo y su salud reproductiva. La tendencia muestra que $70 \%$ de las mujeres radicaban en la misma CDMX. Explicable, si se considera que durante el periodo de observación no solamente era la única entidad que ha despenalizado la ILE por petición de la mujer gestante y, que cuentan con un sistema de 13 clínicas para brindar dicho servicio clínico. Ver siguiente mapa.

Al tener códigos locales que criminalizan el aborto, algunas mujeres que proceden del resto del país acuden a la capital en busca de atención gratuita, segura y confidencial. En orden decreciente, después de la Ciudad de México, ocupan los primeros cinco lugares los estados de: México, Puebla, Hidalgo, Morelos, Jalisco y Querétaro. En las últimas cinco posiciones figuraron: Baja California, Tabasco, Sinaloa, Coahuila y Campeche.

Al interior de las Cámaras de Diputados locales, durante los últimos 12 meses se han estado discutiendo iniciativas sobre la ILE en: Oaxaca, Puebla, Estado de México, Hidalgo y Veracruz. Como lo hemos señalado, recientemente se ha aprobado en el estado de Oaxaca. En Puebla, el Poder Legislativo rechazó la 


\section{Las nuevas narrativas, en el entorno social}

Universidad de La Laguna, diciembre de 2019

DOI (individual): 10.4185/cil2019-número ponencia

ILE. Por lo que corresponde a las tres entidades restantes, continúan en análisis.

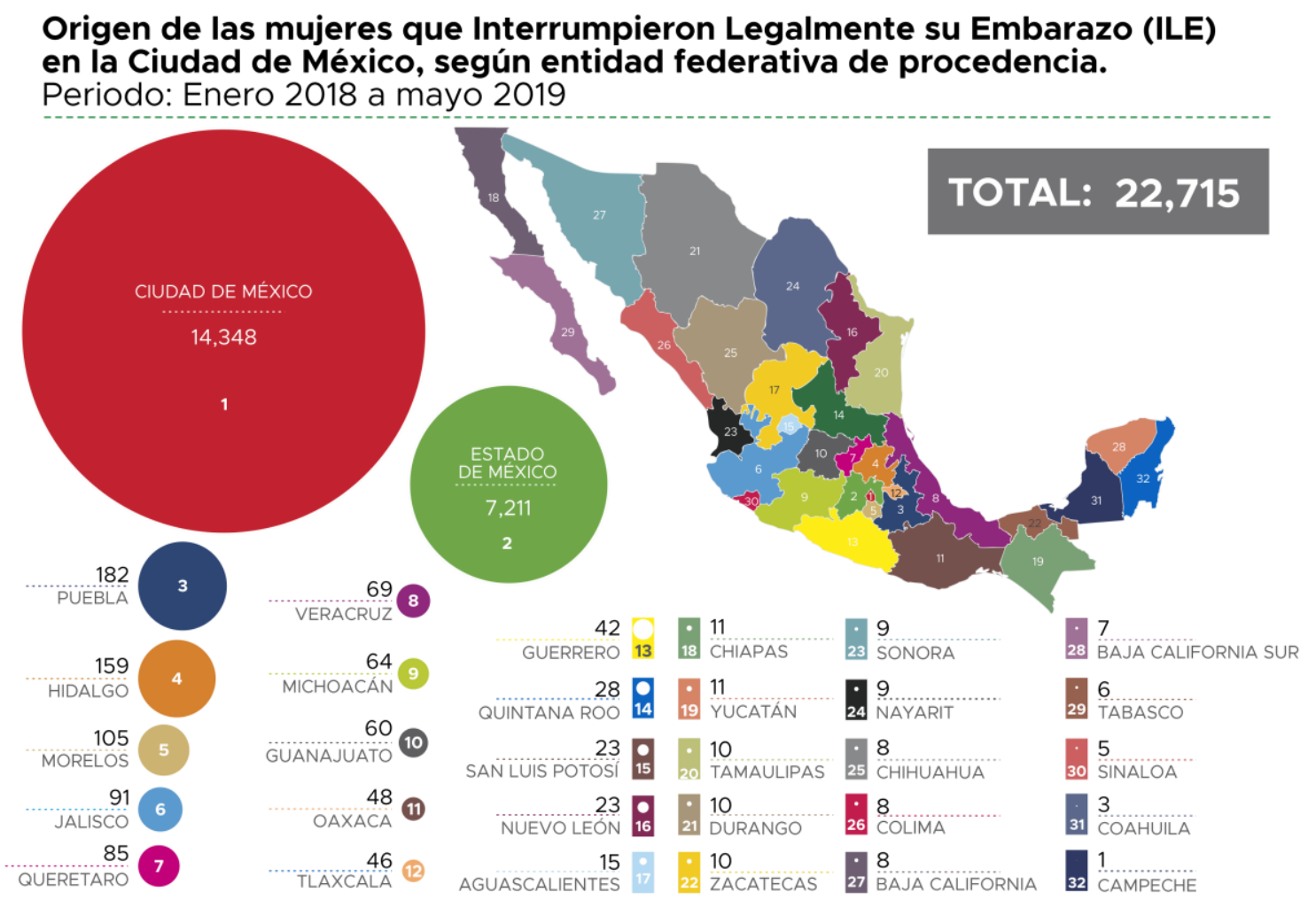

¿Cuál es el perfil social que presentan las mujeres que, entre abril de 2017 y julio de 2018, acudieron a la ILE? En promedio, sobrepasan ligeramente los 25 años de edad. La mitad de ellas tienen 25 años o más; el mayor número de casos se presentó en las mujeres que habían cumplido 22 años de edad. Una de cada cuatro tenía 30 años o más al momento interrumpir su embarazo. Ver siguiente.

Con base en la legislación mexicana, 1,122 de ellas eran menores de edad, ya que tenían entre 17 y 9 años de edad. De ellas, con base en los criterios estipulados por la Organización Mundial de la Salud (OMS) 133 eran niñasadolescentes, pues notificaron tener entre 9 y 14 años de edad. 


\section{Las nuevas narrativas, en el entorno social}

Universidad de La Laguna, diciembre de 2019

DOI (individual): 10.4185/cil2019-número ponencia

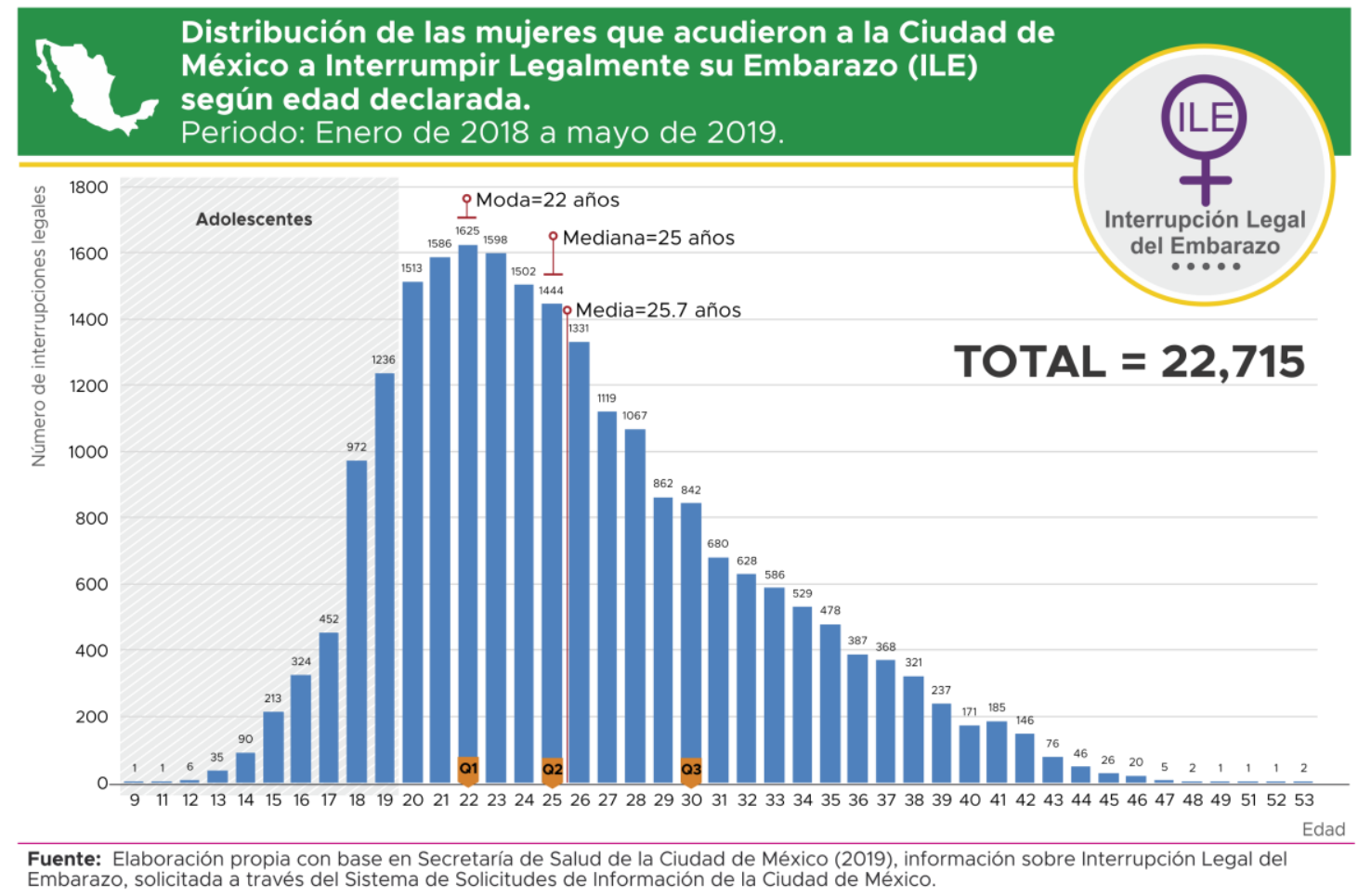

¿Cuántos de esos embarazos no intencionales habrán sido causados por el delito de violación o por estupro? Desconocemos la respuesta pero se avizora una línea de investigación que merece atención y búsqueda de información en las respectivas Fiscalías del país.

Sobre la base de cien casos, quienes tuvieron que acudir a la ILE a la CDMX, 27 tenían estudios de secundaria y 46 contaban con nivel medio superior (bachillerato, en su mayoría). Otras 20 por cada cien, reportaron estudios de licenciatura; cuatro más solamente tenían primaria. Una de cada cien mujeres que decidieron recurrir a la ILE no tenían ningún grado de escolaridad. Al cruzar el nivel de escolaridad con la edad promedio observada, está claro que se trata de una población con rezago educativo o que ha permanecido fuera de las aulas desde tiempo atrás.

Algunos de los planteamientos que han esgrimido quienes se oponen radicalmente a la ILE giran en torno a que, en lugar de salvar una vida (la de la madre) se preserven dos, protegiendo al embrión. Sin embargo, cuando se 


\section{Las nuevas narrativas, en el entorno social}

Universidad de La Laguna, diciembre de 2019

DOI (individual): 10.4185/cil2019-número ponencia

revisan otras variables se puede arrojar más luz acerca de las condiciones socioeconómicas que priman en la mayoría de las mujeres que se vieron impelidas a elegir la ILE. A continuación algunos datos reveladores.

Si bien $70 \%$ de las mujeres manifestaron que contaban con empleo, dado su nivel de escolaridad predominante (secundaria o nivel medio superior) se puede deducir el tipo de trabajo que desempeñan así como la precariedad de sus ingresos. Es revelador que $62 \%$ de todas ellas no contaran con ningún tipo de seguridad social; condición que nos habla de trabajos ligados a la economía informal o mediante esquemas globalizados como la externalización o la subcontratación (outsourcing) sin ningún tipo de prestaciones sociales como lo marca la ley. La quinta parte de los casos informó que era "ama de casa". Al respecto, se trata de una condición más de vulnerabilidad, tanto en lo económico como en la vida cotidiana. Hemos de traer a cuento lo que anotó la sociólogo e historiadora Sara Sefchovich:

"Ama de casa, esa soy yo, ama y señora de mi hogar. Paso el día yendo de un cuarto a otro: aquí tiendo la cama, allá le doy vuelta a la sopa, ahora paso un trapo húmedo y después acomodo, una vez más, los adornos. Esta soy yo, la reina de la casa, la patrona de la licuadora, de la ropa sucia, de las sartenes y la plancha, libre para elegir si gasto mi tiempo en ordenar o en limpiar, si gasto mi dinero en jitomates o en pan, si gasto mi esfuerzo en el mercado o en el salón" (Sefchovich, 2011: 76).

Dicha condición revela, al menos en la quinta parte de ellas, una dependencia - limitación económica que debilita su capacidad para encarar las responsabilidades que exige todo el proceso de gestación y, desde luego, un proceso de crianza y de maternidad que se extenderá impositivamente a lo largo de los años.

Otro argumento es que, según lo afirma el dogma judeo-cristiano y, por extensión la predominante religión católica en México, la vida del ser humano inicia desde el momento de la concepción hasta su muerte. Desde tal precepto, tanto la religión católica como otras creencias emparentadas con los mismos dogmas, esperarían que pocas o ninguna mujer, adscrita a tal credo, debería optar por la ILE. 
Los indicadores generados en este trabajo echan por tierra la idea anterior, pues de las 22,715 mujeres que solicitaron la aplicación de la ILE, durante el periodo procesado, $66 \%$ se declararon católicas, seguidas, con cuatro por ciento del total, de quienes profesaban alguno de los cultos protestantes 0 evangélicos. Cobra relieve un dato más: prácticamente la cuarta parte de los casos no se adscribió a ninguna religión. Como lo han señalado otros autores, en la posmodernidad, asistimos a la desacralización del cuerpo, de la sexualidad y, más recientemente, de la maternidad.

En la línea de que lo minúsculo puede ser revelador, $5 \%$ de ellas prefirió no especificar si formaba parte de alguna religión; quizá porque se trata de un asunto tan íntimo que optaron por no evidenciar un conflicto más a escala mítico-religiosa.

En el debate legislativo, público y tanto mediático como post-mediático se manejan discursos e imágenes difusas que han convenido más a los grupos conservadores que a quienes impulsamos la ILE como un derecho humano que tienen las mujeres para decidir sobre su salud sexual y reproductiva. ¿Cómo se lleva a cabo la ILE? Si bien la legislación en la CDMX y, más recientemente en Oaxaca, indican que dicha interrupción puede efectuarse entre la primera y la doceava semana de gestación, hay pocos datos empíricos que aporten evidencias acerca de lo que está sucediendo con esta técnica y sus métodos. Nosotros hemos querido contribuir para despejar algunas dudas o interrogantes.

El lapso que más frecuentemente utilizaron las mujeres para la ILE, estuvo centrado entre la cuarta y novena semana de gestación, en $88 \%$ de los casos. A continuación el gráfico en la siguiente página.

Desde diversos puntos de vista, es comprensible que durante las primeras tres semanas ocurran muy pocos casos; circunstancias como dudar que pueda tratarse de un embarazo; la esperanza de que no sea así; la falta de recursos 


\section{Las nuevas narrativas, en el entorno social}

Universidad de La Laguna, diciembre de 2019

DOI (individual): 10.4185/cil2019-número ponencia

para la realización de una prueba rápida o de laboratorio que despeje la incertidumbre; la necesidad de ocultar algo posible pero todavía no verificado, puede llevar a muchas mujeres a posponer la toma de decisiones tempranamente. Entre la décima y la doceava, desciende drásticamente y, debemos asumir que se trata de situaciones límite, cargadas de angustia y de no pocas dudas o temores.

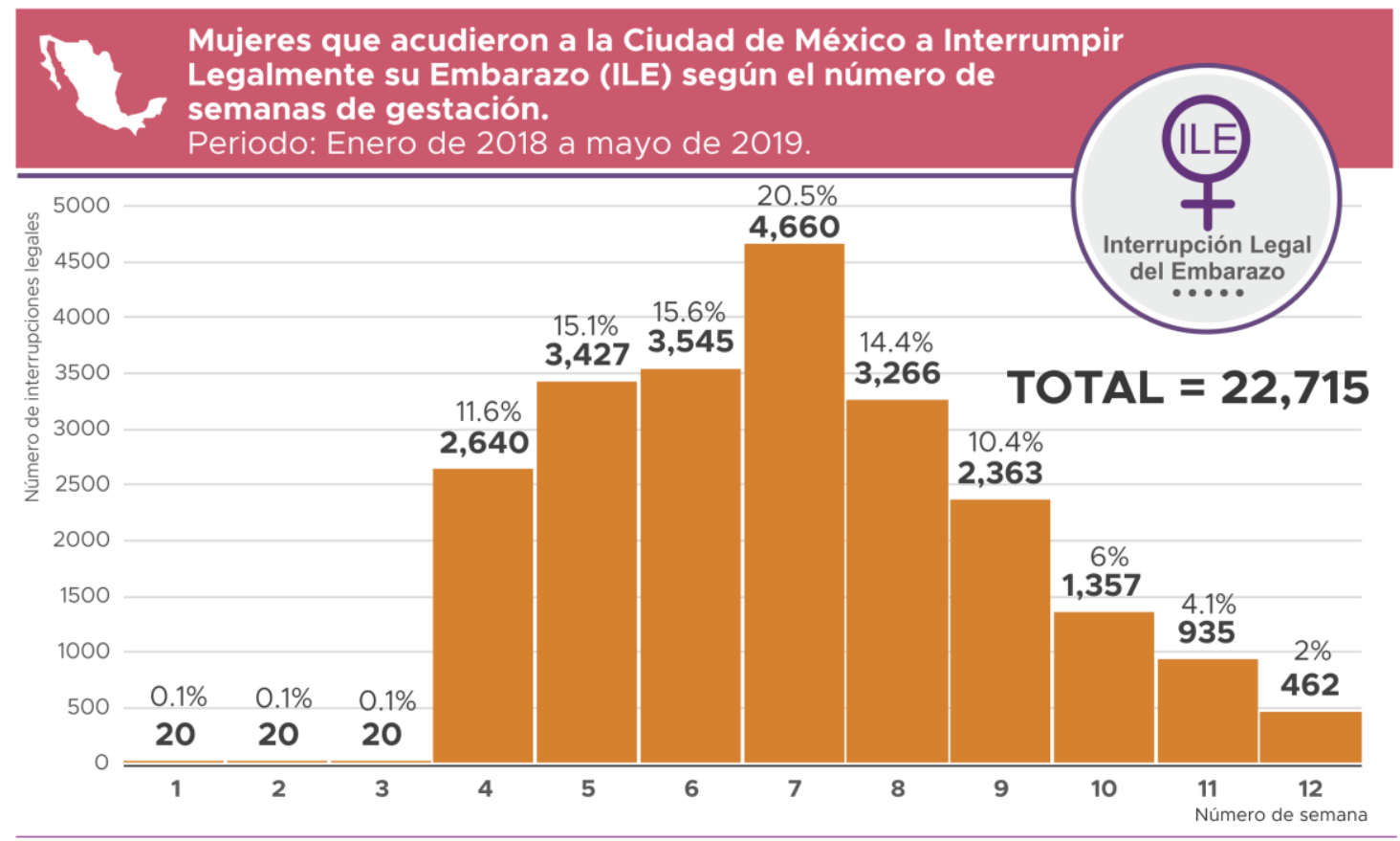

Fuente: Elaboración propia con base en Secretaría de Salud de la Ciudad de México (2019), información sobre Interrupción Legal del Embarazo, solicitada a través del Sistema de Solicitudes de Información de la Ciudad de México.

Por lo que se presenta en los medios de comunicación y, sin duda, por la corrosiva labor que despliegan los grupos conservadores como Provida, continúa gravitando en las mentalidades colectivas -en su mayoría desconectadas con el avance de las ciencias biomédicas y de la farmacología-pervive la idea de que los métodos para efectuar la ILE continúan siendo agresivamente invasivos y que el sufrimiento, peligro de muerte para la madre y el "asesinato" de un ser humano que está formado completamente, serán objeto de una carnicería despiadada.

Como se puede apreciar el la gráfica de la siguiente página, una vez más los datos refutan ese tipo de ideas o imágenes procedentes de otras épocas. Puede verse en el siguiente gráfico cómo, de los casi 23 mil casos registrados 


\section{Las nuevas narrativas, en el entorno social}

Universidad de La Laguna, diciembre de 2019

DOI (individual): 10.4185/cil2019-número ponencia

en la CDMX, procedentes de todo el país, 87 \% fue mediante prescripción y toma de medicamentos.

El $13 \%$ restante, debido al número de semanas transcurridas, requirieron dos técnicas de aspiración (manual o eléctrica), en algunos casos, combinadas con medicamentos. La Edad Media, en este aspecto de la vida humana, ha quedado atrás, al menos en algunos países y regiones del mundo civilizado.

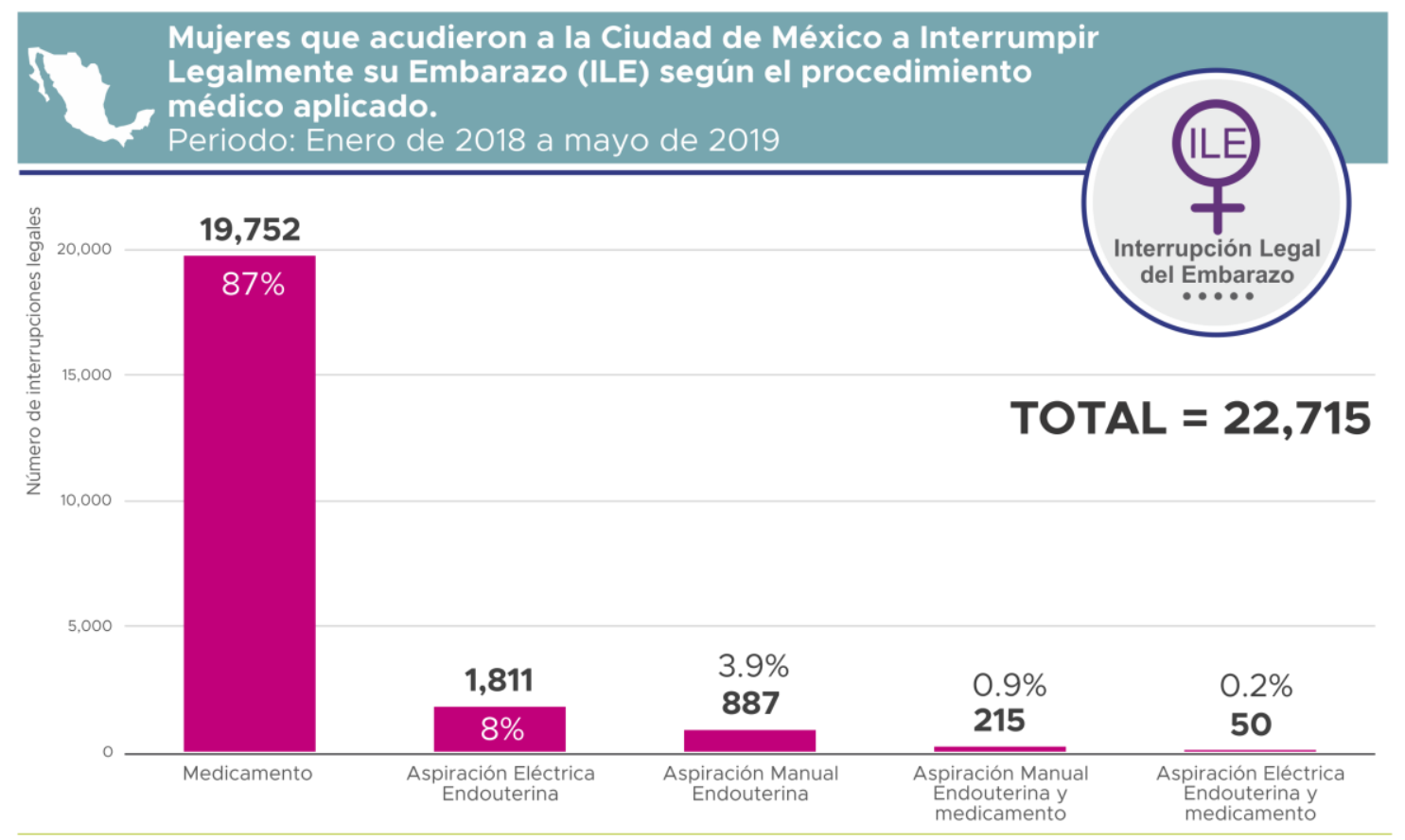

Fuente: Elaboración propia con base en Secretaría de Salud de la Ciudad de México (2019), información sobre Interrupción Legal del Embarazo, solicitada a través del Sistema de Solicitudes de Información de la Ciudad de México.

\section{Discusión y Conclusiones}

La democracia y el ejercicio de las libertades pasan por nuestro cuerpo, en tanto materialidad de nuestra existencia. Si las mujeres están inhabilitadas para decidir si quieren ser madres o no, en ese momento, años más tarde o nunca, entonces no pueden preservar su salud sexual, física en general, psicológica, espiritual ni tomar acciones acerca de un asunto tan trascendental como el hecho de si desean reproducirse o no.

El aborto clandestino ha existido y se mantiene oculto; está claro que se realiza. Sus efectos son letales en tanto causan muchas muertes de mujeres. 
Las ciencias biomédicas, la farmacología, la tecnología, así como la atención clínica segura, gratuita y confidencial están al alcance y constituyen un aporte para la humanidad. Un Estado laico hace uso de los avances científicos y tecnológicos para generar mejores condiciones de vida y para preservar la salud de su población y deja, para el ámbito privado e íntimo, las creencias religiosas que cada uno está en libertad de profesar o defender.

Las mujeres y hombres cuyas convicciones religiosas o morales, ante un embarazo no intencional, deciden continuar con su gestación, están en su legítimo derecho. Pero pretender imponer esa misma decisión a quienes tienen otras ideas, valores y proyectos existenciales, se inscribe en la tiranía, en la intolerancia, en el pensamiento único y, socava nuestras libertades. Por ello, en nuestros cuerpos únicamente debemos mandar nosotros. Nadie más.

La ILE, aunque está circunscrita geopolíticamente a la Ciudad de México y, de manera reciente en el estado de Oaxaca, está atendiendo y protegiendo la vida, así como la dignidad, de un sector femenil vulnerable, que si bien cuenta con empleo, en su mayoría carece de seguridad social y, casi la cuarta parte de ellas no tiene empleo.

En el futuro, cuando todo México disponga de códigos penales vanguardistas, adiós a la clínicas o consultorios encubiertos que realizan esta peligrosa actividad.

Es indispensable que el Estado Mexicano, haga uso de su postura laica para hacer posible que la ILE sea una realidad en todo el país, para beneficio y protección de la salud sexual y reproductiva de las mujeres que, por distintas condiciones y motivos, necesiten optar por la ILE. 


\section{Las nuevas narrativas, en el entorno social}

Universidad de La Laguna, diciembre de 2019

DOI (individual): 10.4185/cil2019-número ponencia

\section{Referencias bibliográficas}

Center For Reproductive Rights (2019): "The World's Abortion Laws":

https://reproductiverights.org/worldabortionlaws [consultado el 22 de septiembre del 2019]

Centro de Derechos Reproductivos (2018): "Panorama mundial del derecho al aborto":

https://www.reproductiverights.org/sites/crr.civicactions.net/files/newsletter/crr s panish globalview.pdf [consultado el 22 de mayo del 2019]

Center for Reproductive Rights (2019): "The World's Abortion Laws":

https://reproductiverights.org/worldabortionlaws [consultado el 22 de mayo del 2019]

Gire (2017): "Violencia sin interrupción": https://aborto-por-

violacion.gire.org.mx/\#/ [consultado el 15 de marzo del 2019]

Guttmacher (2017): "Abortion Legality Worldwide":

https://www.guttmacher.org/abortion-legality-worldwide [consultado el 17 de junio del 2019]

Guttmacher (2018): "Abortion Worldwide 2017: Uneven Progress and Unequal Access": https://www.guttmacher.org/report/abortion-worldwide-2017

[consultado el 18 de junio del 2019]

Guttmacher (2018): "Aborto en América Latina y el Caribe":

https://www.guttmacher.org/es/fact-sheet/aborto-en-america-latina-y-el-caribe [consultado el 19 de junio del 2019]

IPAS México (2019): "Aborto en el Sistema Internacional de Derechos Humanos, México, 2019": https://ipasmexico.org/wpcontent/uploads/2019/documents/WEB-IpasMx2019-ASIDH.pdf [consultado el 22 de mayo del 2019]

IPAS México (2019): "Causales para acceder a un aborto legal":

https://www.ipasmexico.org/wpcontent/uploads/2017/12/CausalesDeAbortoLegal.pdf [consultado el 22 de mayo del 2019]

Lamas, M. (2017): La interrupción legal del embarazo. El caso de la Ciudad de México. México: Fondo de Cultura Económica.

Lerner, Gerda (2017): La creación del patriarcado. Pamplona, España: Katakrak Liburuak.

OMS (2018): "Tratamiento médico del aborto", Ginebra:

https://ipasmexico.org/wp-content/uploads/2019/documents/lpasMx2019-

TMedicoAbortoWHO.pdf [consultado el 10 de octubre del 2019] 


\section{Las nuevas narrativas, en el entorno social}

Universidad de La Laguna, diciembre de 2019

DOI (individual): 10.4185/cil2019-número ponencia

OMS (2019):"Prevención del aborto peligroso": https://www.who.int/es/newsroom/fact-sheets/detail/preventing-unsafe-abortion [consultado el 10 de octubre del 2019]

Secretaría de Salud de la Ciudad de México (2019): "Interrupción Legal del Embarazo": http://ile.salud.cdmx.gob.mx/directorio-clinicas-interrupcion-legaldel-embarazo/ [consultado el 22 de mayo del 2019].

Secretaría de Salud de la Ciudad de México (2019): Información sobre Interrupción Legal del Embarazo. Solicitada a través del Sistema de Solicitudes de Información de la Ciudad de México.

Sefchovich, Sara (2011): ¿Son mejores las mujeres? México: Paidós.

Singh S. (2018): Abortion Worldwide 2017: Uneven Progress and Unequal Access, New York: Guttmacher Institute.

Sucha, M. (2014): "Beyond the Hype: Data Management and Data Governance":

https://mobile.stacksdiscovery.com/eds/detail?db=f5h\&an=95923252\&isbn=001 49802 [consultado el 25 de julio del 2019].

Time (2015):"The most influential images of all time":

http://100photos.time.com/photos/lennart-nilsson-fetus [consultado el $17 \mathrm{de}$ junio del 2019].

Women on Waves (s/f): "Abortion information per Country":

https://www.womenonwaves.org/en/map/country [consultado el 22 de mayo del 2019].

Zimmerman, P. (1994): "La batalla por el cuerpo femenino. Una revaluación de las políticas feministas sobre los medios de comunicación”: Debate Feminista. México: Centro de Investigaciones y Estudios de Género. 